\title{
Pembangunan Tangki Dengan Metode Jack Up
}

\author{
Sulardi \\ Progran studi Teknik Sipil Universitas Tridharma, Jln.A.W Syahrani. No.7, Balikpapan \\ E-mail: sulardikm61@yahoo.com
}

\begin{abstract}
ABSTRA K
Salah satu permasalahan dalam pembangunan tangki adalah sering terjadi kegagalan dalam keberterimaan hasil pengelasan (reject) karena kualitas hasil pengelasan yang tidak sesuai (cacat pengelasan) terutama pada pengelasan yang dilakukan diketinggian. Penelitian ini bertujuan untuk memberikan gambaran tentang pelaks anaan fabrikasi dan pembangunan tangki dengan metode jack up, yakni pekerjaan fabrikasi dan instalasi atap dan shell tangki serta pengelasan yang dilakukan dibawah dipermukaan tanah, setelah selesai fabrikasi kemudian diangkat keatas dengan metode jack up menggunakan hydraulic jack. Hasil penelitian menunjukan metode jack up terbukti memberikan manfaat lebih baik dari aspek panca mutu (kualitas, biaya, waktu, keselamatan dan moral). Hasil penelitian juga menunjukan bahwa fabrikasi dan instalasi tangki dengan metode jack up ini telah direplikasi untuk pembangunan tiga tangki di Pertamina RU V Balikpapan, Pertamina RU IV Cilacap, RU III Plaju dan RU VI Balongan.
\end{abstract}

Kata Kunci :

Cacat pengelasan, hydraulic jack up, panca mutu.

\section{PENDAHULUAN}

\subsection{Latar Belakang Masalah}

Dengan bertambahnya variasi bahan baku crude oil yang diolah dan produk yang dihasilkan di kilang Pertamina RU V Balikpapan, ketersediaan tangki untuk penampungan crude dan produk sangat diperlukan. Dengan bertambahnya variasi ini, service tangki menjadi sedikit berubah bila dibandingkan dengan desain awal pembangunan tangki. Pada program pengembangan fasilitas kilang maka akan dilakukan penambahan fasilitas kilang dengan pembangunan tangki timbun untuk feed intake crude oil dan tangka timbun untuk produksi hasil olahan berupa tangka type fix cone roof dengan kapasitas 180 MB. Tangki didesign sesuai spesifikasi tank service fluids terkait, dan dilengkapi dengan sarana dan fasilitas seperti system piping, listrik dan instrumentasi sistem, fire protection, system venting dan lain-lain yang sesuai untuk menjamin tercapainya aspek safety dan operasional tangki. Pekerjaan fabrikasi dan pembangunan tangka dilingkungan PT. Pertamina RU V Balikpapan adalah salah satu jenis pekerjaan konstruksi yang memerlukan ketelitian dan akurasi tinggi dalam hal kualitas pelaksanaan, keberterimaan dan tergolong sebagai pekerjaan dengan resiko tinggi (high risk). Permasalahan yang dialami pada pekerjaan pembangunan tangki diantaranya :

(1) Pekerjaan di ketinggian sering terhambat, sangat tergantung pada ketersediaan scaffolding

(2) Bekerja diketinggian, rawan terjadi kecelakaan dan terjatuh
(3) Biaya tinggi untuk penyiapan, pengadaan, pemas angan dan pembongkaran scaffolding

(4) Pekerjaan sering terlambat, tidak bisa dis elesaikan on time, dan

(5) Kesulitan melakukan inspeksi karena inspeksi dapat dilakukan diketinggian dan ada ketergantungan dengan scaffolding dan peralatan keselamatan kerja diketinggian $[1,2,3]$.

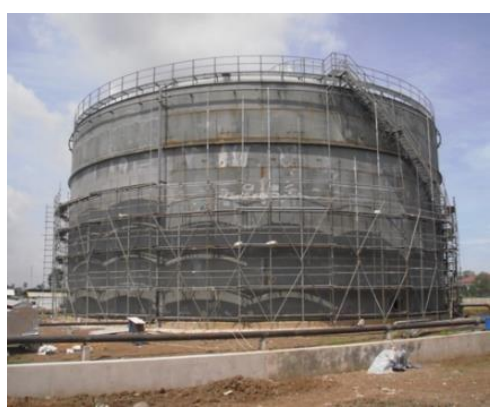

Gambar 1. Kebutuhan scaffold pada pembangunan tangki

Dampak dari permasalahan tersebut adalah kesulitan melakukan pekerjaan erection tangki karena adanya ketergantungan dengan scaffolding dengan potensi keterlambatan penyelesaian pekerjaan selama 2,5 bulan. Belajar dari kesulitan tersebut maka pelaksanaan fabrikasi dan pembangunan tangki akan dilakukan inovasi dengan modifikasi metode fabrikas i dan pembangunan tangki dari metode manual menjadi metode hydraulic jack up. 


\subsection{Permasalahan Penelitian}

Permasalahan yang dihadapi adalah adanya ketergantungan dengan alat scaffolding untuk bekerja diketinggian dan terjadinya cacat pada pengelasan dan tidak diterimanya hasil pengelasan (reject) pada pekerjaan fabrikasi dan instalasi bangunan tangka $[2,3]$. Cacat pada pengelasan dan tidak diterimanya hasil pengelasan ini karena tidak sesuainya hasil pekerjaan pengelasan dengan kriteria keberterimaan hasil pengelasan (quality acceptance criteria).

Diprediksi faktor penyebab sering terjadi cacat hasil pengelasan adalah tingkat kesulitan yang tinggidalam pelaksanaan pengelasan yang dilakukan dilokasi ketinggian. Untuk itu penelitian ini sangat penting dilakukan dalam rangka menemukan jawaban atas pertanyaan mengapa sering terjadi kegagalan dalam keberterimaan (reject) hasil pengelasan tangki yang dilakukan diketinggian dengan cara memodifikasi pelaksanaan pekerjaan fabrikasi dan instalasi tangki yang semula dilakukan secara manual menjadi metode hydraulic jack up. Metode hydraulic jack up adalah metode fabrikasi dan pembangunan tangka dilakukan dipermukaan tanah dan dilakukan pengangkatan bangun tangki setelah seluruh rangkaian pekerjaan difabrikasi, instalasi dan inspection test selesai dilakukan serta dinyatakan diterima.

\subsection{Tujuan Penelitian}

Tujuan yang hendak dicapai melalui kegiatan penelitian ini adalah :

1. Memberikan gambaran metode fabrikasi dan pembangunan tangka dengan metode hydraulic jack up.

2. Memberikan gambaran potensi manfaat dan potensi permasalahan fabrikasi dan pembangunan tangka dengan metode hydraulic jack.

\subsection{Pertanyaan Penelitian}

Pertanyaan-pertanyaan yang dikembangkan melalui kegiatan penelitian ini adalah :

1. Bagaimana gambaran metode fabrikasi dan pembangunan tangka dengan metode hydraulic jack up

2. Bagaimana gambaran potensi manfaat dan potensi permasalahan fabrikasi dan pembangunan tangka dengan metode hydraulic jack up.

\section{TINJAUAN PUSTAKA}

Tangki timbun (tanked farm) adalah alat penimbunan dan penampungan minyak mentah (crude oil) bahan baku kilang pengolahan minyak (refinery) dan bahan bakar minyak hasil produksi pengolahan kilang. Struktur bangunan tangki terdiri dari dari dua bagian utama, yaitu struktur bangunan atas yang terdiri dari roof (atap), shell plate (dinding) dan pelat lantai (bottom plate) [4]. Struktur bangunan bawah terdiri dari pondasi tangki, sistim drainase, sewer dan bundwall tangki. Metode fabrikasi dan pembangunan tangki yang dianggap paling cocok dan sesuai dikembangkan pada saat ini di lingkungan Pertamina adalah metode hydraulic jack up. Metode hydraulic jack up adalah cara membangun tangki dengan melakukan fabrikasi bagian roof dan dinding tangki dibawah dan untuk pemasangan shell course bagaian bawah dengan cara mengangkat dengan alat jacking. Metode hydraulic jack up pada pekerjaan fabrikasi dan pemasangan tangki dimaksudkan untuk mempermudah pelaksanaan pekerjaan instalasi tangki dengan meminimalkan sambungan las shell plate dinding tangki dibagian atas. Ruang lingkup pekerjaan pekerjaan pembangunan tangki meliputi pekerjaan fabrikasi, pekerjaan pembangunan, erection dan pengujian tangki, penggunaan peralatan kerja dan pemilihan tenaga kerja dengan kompetensi yang memadai. Pemasangan tangki dengan metode hydraulic jack up efektif diaplikasikan untuk tangki dengan tiang roof sedikit. Jika desain menghendaki penggunaan tiang roof cukup banyak maka diusahakan jarak antar tiang sejauh mungkin/ penggunaan tiang seminimal mungkin dengan penyesuaian dimensi konstruksi raft dan kolom. Konstruksi tiang/kolom juga dihindari banyaknya sambungan las karena potensi korosi tinggi terhadap kolom/tiang rangka atap.

\section{METODE PENELITIAN}

\subsection{Lokasi dan Pembatasan Penelitian}

Penelitian ini dilakukan di kilang Pertamina RU V Balikpapan bersamaan dengan pelaksanaan pembangunan tiga unit tangki. Pada penelitian ini penelitian sekaligus melaksanakan tugas sebagai construction Inpection Engineer [1,2,3,5] dan bertanggungjawab terhahap kualitas hasil pekerjaan fabrikasi dan instalasi tangka. Kegiatan penelitian ini membatasi ruang lingkup penelitian pada metode pelaksanaan fabrikasi dan instalasi tangka yang dilakukan dengan metode hydraulic jack up, potensi manfaat dan potensi permasalahan pada pelaksanaan metode hydraulic jack up.

\subsection{Metode Pendekatan Penelitian}

Penelitian ini menggunakan metode penelitian aplikasi yakni aplikasi metode hydraulic jack up pada kegiatan fabrikasi dan instalasi tangka [2]. Penelitian ini sekaligus adalah catatan success story aplikasi cara pengangkatan tangki dengan metode 
hydraulic jack up. Pelaksanaan penelitian ini menggunakan metode pendekatan studi kasus, yakni kasus penanganan masalah sering terjadi kegagalan (reject) hasil pengelasan yang dilakukan diketinggian dengan pengelasan tangki dipermukaan tanah, setelah fabrikasi dan pengelasan instalasi tangki selesai maka bangunan tangki diangkat keposisi sambungnya dengan alat hydraulic jack up.

\subsection{Bahan Penelitian}

Bahan-bahan yang diperlukan pada pelaksanaan pekerjaan perbaikan pondasitangki meliputi :

a. Bangunan tangki dan unit pelengkapnya

b. Pelat dan bahan-bahan pengelas an

c. Bahan-bahan lain sesuai kebutuhan.

\subsection{Peralatan Penelitian}

Peralatan kerja digunakan terdiri dari :

a. Alat Hydraulic jack 10 MT/ 12 MT Capacity

b. Hydraulic jack with power pack dan kelengkapannya

c. Alat angkat bantu, tackles dan derick

d. Pipa \& plate bending machine

e. Peralatan transport

f. Bending machine/ mesin pengerol pelat

g. Alat keselamatan kerja dan Alat pelindung diri

h. Alat bantu testing dan pengujian

i. Alat bantu kerja lainnya sesuai kebutuhan dan sesuai kondisi di site.

\subsection{Metode kerja Pekerjaan persiapan} (Preparation) [6]

a. Sebelum memulai pekerjaan disiapkan fasilitas screen water bentuk spray water dengan ketinggian permanent min. 2.0 meter diatas pekerjaan. Screen water berjarak maks. $20 \mathrm{~cm}$ sehingga dapat menutup celah uap minyak pavour dengan baik dan aman. Struktur penopang screen water agar dipastikan kokoh dan stabil terhadap tekanan angin

b. Sebelum memulai pekerjaan agar dipastikan material pelat, sambungan, asesoris dan komponen tank systemtelah tersedia lengkap dan dicatat didalam check list

c. Sebelum memulai pekerjaan fabrikasi dipastikan bahwa seluruh material yang akan digunakan telah teridentifikasi, telah dilakukan marking, pemotongan, pengerolan, dan tata cara pengelasan sesuai prosedur pengelas an API 650

d. Sebelum memulai pekerjaan fabrikasi agar dipastikan bahwa tenaga kerja telah sesuai kualifikai yang dipersyaratkan, memahami aspek safety dengan baik, memahami aspek Quality control dan metode pengujian NDT yang akan digunakan dengan koordinasi yang baik tenaga ahli e. Lay out, konfigurasi fabrikasi pelat, struktur dan perpipaan serta pekerjaan-pekerjaan prioritas fabrikasi telah dilakukan pengecekan terhadap seluruh dimensi dengan baik dan benar

f. Menyiapkan marking komponen sesuaidrawings

g. Sebelum memulai pekerjaan fabrikasi dan pembangunan tangki dengan metode jack up dipastikan bahwa pondasi tangki telah selesai, bentuk, dimensi dan konfigurasi pemasangan pondasi telah sesuai dan telah aman untuk dilakukan pembangunan (erection) tangki diatasnya.

\subsection{Pelaksanaan Fabrikasi (Fabrication) [6]}

a. Seluruh pelat, fitting/ sambungan, asesoris dan komponen lain tankage system agar di-marking dan diberi tanda-tanda yang jelas dan tidak mudah hilang dan diberi tanda dengan joint number untuk setiap urutan pengelasan (welder number)

b. Semua pekerjaan fabrikasi meliputi identifikasi material, marking, pengerolan dan pengelasan harus dilakukan sesuai prosedur kerja yang telah ditentukan dan sesuai standar API 650 Last edition. Pekerja yang melakukan pekerjaan telah memahami dengan baik dan benar aspek keselamatan kerja, quality control dan pengujian NDT serta selalu berkoordinasi dengan Engineer In-Charge yang meliputi :

1) Fabrikasi dan pengujian pekerjaan annular plate \& bottom plate sesuai spesifikasi standar API 650

2) Fabrikasi dan pengujian hasil pekerjaan fabrikasi shell plate sesuai spesifikasi standar API 650

3) Fabrikasi dan pengujian hasil pekerjaan struktur roof plate sesuai spesifikasi dan drawing

4) Fabrikasi dan pengujian hasil pekerjaan asesoris dan kelengkapan tangki sesuai spesifikasi standar dan sesuai drawing

5) Fabrikasi dan pemeriksaan pekerjaan spiral stairway dan handrail sesuai spesifikasi standar dan sesuai drawing.

\subsection{Pelaksanaan Pembangunan Tangki (Erection)}

[6]

a. Melakukan pekerjaan Pemasangan Annular plate layer

Pekerjaan pemasangan annular plate layer dilaksanakan setelah dipastikan bahwa level pondasi telah diinstal sesuai spesifikasi API 650 (Klausul 8.4.2). Setelah dilakukan clearance 
terhadap layer annular plate, lakukan marking dengan posisi koordinat $0^{\circ}, 90^{\circ}, 180^{\circ}$, dan $270^{\circ}$ pada pondasi terpasang sebagai reference point. Selanjutnya lakukan pemasangan annular layer plates sesuai drawing dengan tahapan sebagai berikut.

1) Radius luar annular plates harus pada posisi positive side $(5.0$ to $10 \mathrm{~mm})$ dan sesuai drawing

2) Pengelasan dilakukan oleh welder yang berkualifikasi dan bersertifikasi migas

3) Setelah selesai pengelasan permukaan dibersihkan dengan wire brushing dan gerinda

4) Lakukan pengujian hasil pengelasan secara visual (visual test) dan radiography sesuai API-650 Sec-6.

b. Melakukan Pekerjaan Pemasangan Bottom plate layer (bootom plate layer)

1) Pasang layer bagian center bottom plate diatas pondasi tangki sesuai drawing

2) Mengatur susunan bottom plate, dimulai dari center bottomplate sesuai drawing

3) Overlaps plate dilakukan pada saat melakkukan pekerjaan fit-up kearah memanjang dan melintang bottom plate sesuai drawing

4) Setelah fit-up selesai dilanjutkan dengan tack weld kearah memanjang dan melintang bottom plate sehingga posisibottomplate tidak bergerak/ tidak bergeser dan patikan bottom plate tersusun dengan rapat (tidak ada celah)

5) Melaksanakan pengelasan mulai dari posisi melintang pelat, lanjut kepada posisi memanjang pelat dan dipastikan tidak terjadi avoid distortion

6) Setelah pekerjaan pengelasan selesai, lakukan remove temporary tacks welds dengan cara menggerinda dan dilakukan fit-up lagi terhadap posisi layer bottom plate kemudian dilakukan pengelasan secara lengkap sesuai prosedur dan spesifikasi pengelas an

7) Setelah seluruh pekerjaan pengelasan selesai (completed) dilakukan cleaning weld joint dengan wire brushing dan gerinda

8) Minimum over laps bottom plates sesuai standard \& code API 650 dan sesuai drawing

9) Kualifikasi welder sesuai kualifikasi dan bersertifikasi Migas serta memahami dengan baik welding procedure system(WPS) pengelasan

10) Seluruh bottom plate's joints dilakukan pengujian dengan vaccum box test sesuai prosedur dan spesifikasi pengujian vaccum test box

11) Jika ditemukan cacat (defect) atau indikasi cacat (initial defect) pengelas an agar dilakukan perbaikan dengan cara menggerinda dan re-weld serta melakukan uji vaccumbox test.

3.8 Melakukan pekerjaan Pemasangan Shell plate (Shell Course Erection) [6]

a. Setelah pekerjaan pengelasan annular plates dan bottom plates selesai (comple ted), lakukan marking inner radius tank diatas annular plates

b. Sheel course paling atas (top one shell course) dilakukan pemasangan secara konvensional (conventional method)

c. Pemasangan (erection) shell plate (shell course) dengan metode hydraulic jack up (hydraulic jack up method) dilakukan dengan memperhatikan keseimbangan shell course

d. Shell plate (shell course) yang telah diroll dilakukan handling menggunakan hydra crane dengan hati-hati

e. Pemasangan shell plate pada diameter marked (marking dimensi tangki) diatas annular plate sesuai align sheel plate

f. Lakukan fit-up shell plate secara completed kecuali bagian segment final joint yang akan fitup dan dilakukan pengelasan setelah selesainya pengelas an sheel joint (to avoid the shrinkage)

g. Pemeriksaan peaking (gembung) dilakukan setelah fit-up vertical joint shell plate. Actual peaking tolerance harus sesuai standard API-650 (tolerance. $1 / 2$ inch)

h. Pemeriksaan peaking dilakukan pada shell course atas (top), tengah (middle) dan shell course bagian bottom pada vertical joint dengan jangkauan. 36 inch panjang

i. Plumbness shell tangki harus dicheck verticality nya setiap 600 dan harus dalam batas tolerance (batas toleransi plumbness : 1/200 tinggi total shell) dan untuk kesempurnaan verticality maka dipasang channel pada internal sheel course dengan interval 3-5 m dan pengelasan dengan smooth setelah dilakukan inspeksi terhadap hasil fit-up dan back chipped grooves

j. Lanjutkan erection last shell course (mengangkat plat sheel) diatas posisi shell plate (lower plate) yang akan dipasang dengan $3.0 \mathrm{~mm}$ thick spacers dan dilakukan erection channel dengan interval 3-5 meter untuk menjaga verticality sheel plate

k. Setelah shell plate terpasang lakukan pemeriksaan visual, peaking dan circumference, pastikan kondisinya sesuai standard API650, hasil pemeriksaan dicatat didalam format hasil pemeriksaan ileh Engineer-In-Charge

1. Instal spiral staircase termasuk bracketnya se suai drawing

m. Pemasangan jack up sesuai sesuai requirement dengan jarak tidak melebihi $3.50 \mathrm{~m}$ dan 
interkoneksi dengan power pack sehingga total system siap untuk erection

n. Jacking shell plate dengan jarak antara sheel plate yang diangkat (last shell plate) dengan pelat dibawahnya (lower plate) 40-45 Cm, pastikan verticality, peaking dan plumbness shell plate dalam batas toleransi

o. Jika ditemukan cacat (defect found) agar segera dilakukan repair dengan cara menggerinda diarea yang rusak ditambah dengan jarak $150 \mathrm{~mm}$ dari lokasi cacat kedua arah kerusakan sesuai requirement Engineer-In-Charge

p. Pemeriksaan akhir hasil pemasangan shell plate meliputi pemeriksan cisual (VT) dan uji radiography test oleh Engineer-In-Charge sesuai standard API-650 Sec-6

\subsection{Melakukan Pemasangan Cone Roof [6]}

a. Pemasangan struktur cone roof dilakukan setelah 2 (dua) sheel shell course terpasang, telah dilakukan fit-up, pengelasan dan telah dilakukan fit up ring dan telah dilakukan pengelasan secara komplit

b. Pemasangan center drum, roof truss dan cross girders sesuai drawing, dilanjutkan dengan pemasangan dan lay out roof plate pada struktur sesuai drawing serta lakukan pengelasan sesuai WPS

c. Roof nozzle dan top sheel nozzle fit up serta pengelasan harus sesuai drawing sesuai dengan sequen dan tetap memperhatikan rencana pemasangan perpipaan sesuai drawing

d. Melakukan pekerjaan tangga spiral, stairway, hand rail dan asesoris penunjang operasi dan pemeliharaan tangki.

\subsection{Melakukan Instalasi Perlengkapan dan alat kelengkapan tangki) [6]}

a. Sambungan flange ke perpipaan harus telah difabrikasi dan dilakukan pengujian NDT sebelum dilakukan erection

b. Lakukan marking lokasi nozzle sesuai drawing dan lakukan cut opening setelah dilakukan inspeksi oleh Inspektor yang berwenang

c. Pasang nozzle dengan bentuk dan konfigurasi pemasangan sesuai drawing

d. Instal pads flange sebelum dilakukan pemasangan nozzle

e. Setelah bottol shell course lengkap terpasang, shell nozzle harus di-marking sesuai drawing dan sesuai hasil inspeksi f. Lakukan cut open nozzle opening, install pads dan lakukan pemasangan nozzles yang dengan bentuk dan konfigurasi sesuai drawing

g. Jika ada perubahan installs berdasarkan hasil inspeksi akhir agar dituangkan dalam drawing akhir (as built drawing)

h. Pengelasan dilakukan sesuai welding procedure system (WPS) dan dilakukan oleh welder yang berkualifikasi

i. Man-Hole neck harus telah difabrikasi dan telah dilakukan pengujian las-lasan dengan radiografhi

j. Seluruh pad telah dilakukan uji pneumathic dengan tekanan $1.05 \mathrm{~kg} / \mathrm{cm} 2$ dan disaksikan oleh Inspection In charge dan Engineer in charge

k. Seluruh shell nozzle dan pad yang telah selesai dilakukan pengelasan harus telah lolos uji visual (VT) oleh Inspector in charge (IIC) dan Engineer in charge (EIC).

\subsection{Kualitas Penerimaan, Kontrol kualitas pekerjaan dan Keselamatan kerja [7]}

a. Pelaksanaan pekerjaan pembangunan dan perbaikan tangki harus mengikuti prosedur, drawing, spesifikasi, standard \& code yang telah ditetapkan pertamina

b. Melaksanakan prosedur keselamatan kerja dengan baik pada saat melakukan pekerjaan

1) Telah dilakukan pengujian dan sertifikasi peralatan angkat dan dilakukan pengangkatan sesuai hasil pengujian

2) Sfatey precaution harus dilakukan dan diikuti selama pelaksanaan pekerjaan fabrikasi dan pembangunan tangki

3) Welding cables (kabel untuk pengelasan) harus sesuai standard dan terproteksi dengan baik dan aman

4) Lokasi kerja (fabrikasi dan pembangunan tangki) haris dijaga agar tetap bersih dan rapih

c. Dilakukan pencatatan (records) dan pelaporan terhadap :

1) Pekerjaan struktur pondasi

2) Kegiatan terkait dengan pengadaan, pemeriksaan dan penggunaan material

3) Kegiatan terkait dengan pengadaan electrode dan catata verifikasi material

4) Welding inspection report

5) NDT reports

6) Metode melakukan pengujian dan hasil testing reports. 


\subsection{Indikator dan Ukuran Keberhasilan}

a. Spesifikasi material yang digunakan sesuai spesifikasi, standard \& code API 650

b. Pekerjaan persiapan, bahan, peralatan, tenaga kerja, metode kerja fabrikasi dan pemasangan struktur bottom plate, struktur shell plate, struktur roof plate dan peralatan maupun perlengkapan penunjang operasional dan pemeliharaan tangki dapat diselesaikan dengan baik dan aman

c. Hasil pekerjaan fabrikasi dan pemasangan bottom plate, struktur shell plate, struktur roof plate dan peralatan maupun perlengkapan penunjang operasional dan pemeliharaan tangki telah lolos uji/ pemeriksaan visual test, NDT dan radiography test sesuai spesifikasi standard \& code API 650 dan comisioning test

d. Mentaati peraturan keselamatan kerja dengan baik dan tidak terjadi accident.

\section{HASIL DAN PEMBAHASAN}

Penggunaan metode hydraulic jack up terbukti dapat mengatasi kesulitan metode erection tangka di Pertamina RU V Balikpapan. Metode kerja fabrikas i dan instalasi tangki dengan metode hydraulic jack up telah dibakukan sebagai standar kerja baku dengan No.012/E15220/2015-S2 [7] dengan prinsip kerja pembangunan tangka dengan metode jack up meliputi :

(1) Proses Erection jack up tank diawali dengan memasang angular plate, bottom plate, shell plate course ke- 1 dan ke- 2 paling atas, memasang rafter, memasang roof plate, memasang roof nozzle dan memasang roof accessories tanki lainnya sesuai dengan drawing desain

(2) Pekerjaan pengelasan shell plate telah dilakukan penuh (full welding)

(3) Selesai pengelasan dilakukan Inspeksi dan Testing NDT

(4) Proses dilanjutkan dengan mengangkat dan memasang shell plate ke tiga paling atas sampai dengan shell paling bawah, shell nozzle serta asesoris tangki lainnya.

Tahap preparasi dilakukan dengan pengerolan shell plate. Dan secara parallel disite dilakukan preparasi dan setting alat hydraulic jack up kapasitas alat 30 ton sebanyak 24 set, dengan satu unit pompa dan satu unit manipole.

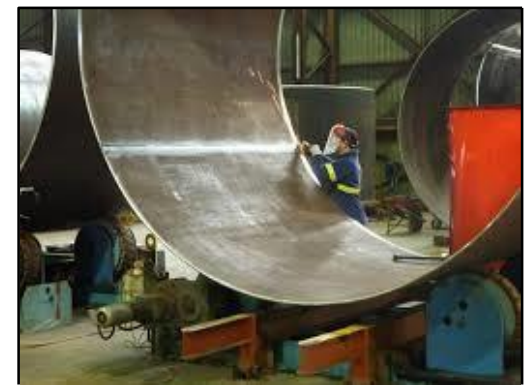

Gambar 2. Rolling shell plate

Secara parallel disite dilakukan preparasi dan setting alat hydraulic jack up kapasitas alat 30 ton sebanyak 24 set, dengan satu unit pompa dan satu unit manipole.

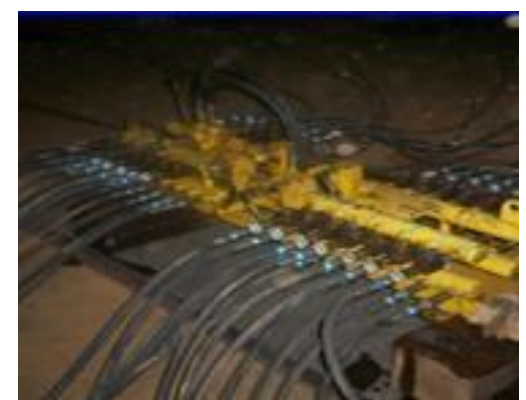

Gambar 3. Setting alat hydraulic jack up

Tahap pelaksanaan erection instalasi tangki meliputi (1) setting bottom plate (2) erection shell plate course atas, layer no.2 dan fit-up welding vertical dan horizontal (3) melakukan full weld (4) setelah shell plate no.1 dan no. 2 selesai dilakukan full weld dilanjutkan dengan erection top angle dan rafter (5) erection shell plate coarse atas no.3, fit up dan ful weld (6) melakukan fit up dan full weld wind girder (7) erection, fit up dan full weld shell coarse paling bawah (8) erection fit up dan full weld shell nozzle dan assesoties (9) ecerection complete (10) touch up dan coating.

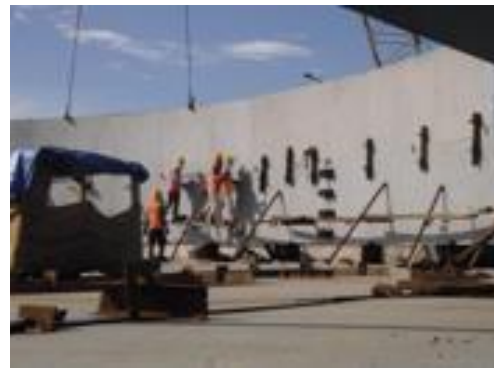

Gambar 4. Setting shell plate 


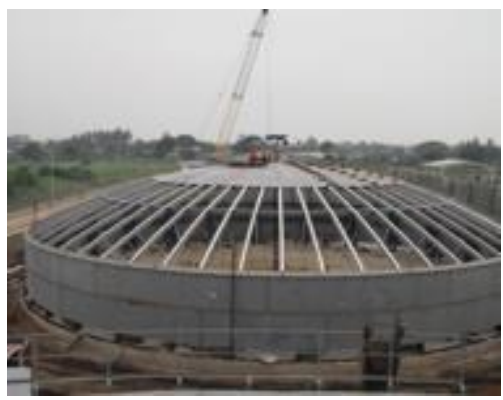

Gambar 5. Instalasi cover top

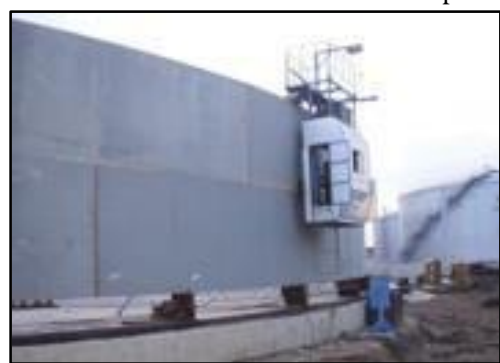

Gambar 6. Automatic weld

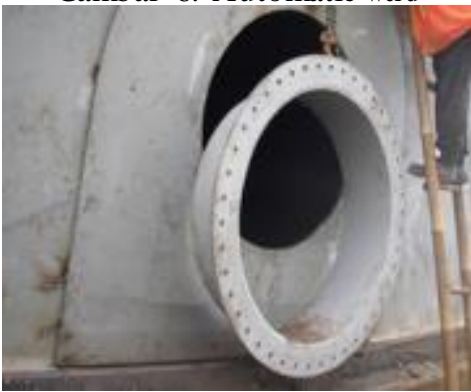

Gambar 7. Pemasangan assesories

Hasil perbaikan dari aspek panca mutu menunjukan, secara mutu (quality) hasil inspeksi dan uji NDT, Kualitas hasil instal dan pengelasan lebih baik, potensi kerja ulang dapat ditekan. Secara biaya (cost) dapat menghemat biaya pelaksanaan sebesar $\mathrm{Rp} \quad 2.700 .000 .000,00$. Secara delivery dapat mempercepat waktu pelaksanaan dalam 2,5 bulan dengan kemudahan pekerjaan instalasi maupun inspeksi karena seluruh pekerjaan instalasi dilakukan

dipermukaan tanah dan tidak tergantung ketersediaan scaffolding. Dari aspek safety menunjukkan bahwa potensi terjadi kecelakaan kerja, terjatuh dan fatality dapat ditekan. Dan dari aspek moral menjadikan pekerja lebih konfiden dengahn inovasinya yang dapat mengatasi masalah dengan baik dan aman.

\section{KESIMPULAN DAN SARAN}

\subsection{Kesimpulan}

1. Metode hydraulic jack up terbukti cocok dan sesuai digunakan untuk fabrikasi dan instalasi bangunan tangki serta bermanfaat dapat mengatasi kesulitan metode erection tangka di Pertamina RU V Balikpapan
2. Keberhasilan metode kerja fabrikasi dan instalasi bangunan tangki dengan metode hydraulic jack up telah dibakukan sebagai standar kerja baku di Pertamina RU V dengan standar kerja baku No.012/E15220/2015-S2.

\subsection{Saran}

1. Metode hydraulic jack up yang terbukti cocok dan sesuai digunakan untuk fabrikasi dan instalasi bangunan tangki baru dapat digunakan pada pekerjaan maintenance dan overhaul tangka di Pertamina RU V

2. Keberhasilan metode kerja fabrikasi dan instalasi dengan metode hydraulic jack up yang telah dibakukan sebagai standar kerja baku dapat direplikasi untuk mengatasi permasalahan sejenis di unit kerja di luar Pertamina.

\section{DAFTAR PUSTAKA}

[1] Sulardi, 2016, Erection dan Instalasi Pembangunan Tangki Dengan Metode Jack Up Di RU $V$ Balikpapan, Materi Sharing Knowledge PT. Pertamina RU V, Balikpapan

[2] Sulardi, 2016, Mengatasi Kesulitan Erection Pada Pembangunan Tangki Dengan metode Top Down Jack Up System Di RU V Balikpapan, Risalah Continuous Program PT. Pertamina RU V, Balikpapan

[3] Sulardi, 2016, Menekan Potensi Cacat Pengelasan Pekerjaan Pengelasan Tangki Dengan Metode Jack Up, http: http://ptmkpwab81.pertamina.com/komet/Doku men_Detail.aspx?ptm=jFPUooHNu+fmAH\%2 fkxzp2mqqhkJnHmpx4mJtEYb5ebmE\%3d, Kodefikasi No.160606004

[4] API Standard 650, 2013, Welded Tanksfor Oil Storage

[5] Sulardi, 2016, Fabrikasi dan Instalasi Tangki Dengan Metode Jack up, Pertamina RU V, Balikpapan.

[6] TKI No. C-009/E15154/2015-S0, 2015, Perbaikan Tangki Timbun, Pertamina RU V, Balikpapan

[7] TKI No. C-012/E15220/2015-S0, 2015, Melaksanakan Fabrikasi dan Instalasi Tangki Dengan Metode Jack up, Pertamina RU V, Balikpapan

[8] TKI No. C-009/E15154/2015-S0, 2015, Perbaikan Tangki Timbun, Pertamina RU V, Balikpapan 